\title{
Correction to: QTL mapping of flowering time and biomass yield in tetraploid alfalfa (Medicago sativa L.)
}

Laxman Adhikari, Shiva Om Makaju and Ali M. Missaoui

Correction: BMC Plant Biology (2019) 19:359

https://doi.org/10.1186/s12870-019-1946-0

In the article [1], in 'Methods' section and ' $G \times \mathrm{E}$ and heritability' subsection, there is an error in the formula of heritability $\left(\mathrm{H}^{2}\right)$.

The correct formula should be

$$
\mathrm{H}^{2}=\frac{\sigma^{2} \mathrm{~g}}{\sigma^{2} \mathrm{~g}+\frac{\sigma^{2} \mathrm{r}+\sigma^{2} \varepsilon}{\mathrm{r}}}
$$

The original publication has been corrected.

Published online: 28 October 2019

\section{Reference}

1. Adhikari L, et al. QTL mapping of flowering time and biomass yield in tetraploid alfalfa (Medicago sativa L.). BMC Plant Biol. 2019;19:359. https://doi.org/10.1186/ s12870-019-1946-0. 